\title{
A ESCOLA DA PERIFERIA: ESCOLARIDADE E SEGREGAÇÃO NOS SUBÚRBIOS*
}

\author{
Maria Drosila Vasconcellos ${ }^{* *}$
}

$\mathrm{O}$ objeto desse livro organizado em torno da noção de "escola da periferia" é fundamentalmente o de abordar as desigualdades escolares que se devem às diferenças espaciais, isto é, ao fato de o trabalho pedagógico, os conteúdos de ensino e as expectativas dos docentes para com as aquisições dos alunos diferirem de um estabelecimento a outro em função de sua localização geográfica. A autora, a socióloga Agnès Van Zanten, vem se interessando pelas diferenças locais ou as questôes urbanas em relação aos problemas escolares desde os anos de 1980 e trabalhou com collèges e lycées (colégios de segundo ciclo do ensino fundamental e de ensino médio) primeiro na periferia de Lyon e depois nos subúrbios parisienses. Neste último caso, ela cotejou os estabelecimentos escolares com recrutamentos diferenciados segundo as origens sociais dos alunos (pais operários ou assimilados e de origem estrangeira e pais das classes médias ou altas). Esses estudos a levaram a apresentar vários trabalhos sobre a segregação social e suas relações com a segregação escolar. Emprestada da sociologia urbana, essa noção de segregação revela as interações que se estabelecem entre as questóes da escola e as dinâmicas sociais no plano local ou nacional. Com essa abordagem, os problemas de escolaridade ultrapassam a focalização em questôes centradas na própria escola.

É preciso salientar que, na França, a institucionalização de um sistema educativo centralizado nasceu da inspiração da Filosofia das Luzes e foi implementada pelos responsáveis da Terceira República, para dar a todas as crianças as mesmas condições de aprendizagem.

\footnotetext{
* Resenha do livro de Agnès Van Zanten, L'école de la périphérie. Scolarité et ségrégation en banlieue (Paris: PUF, 2001. 425p. Coll. Lien Social), traduzida por Alain François.

** Professora de Sociologia da Educação na Université Lille 3, França. E-mail: vasconcellos@wanadoo.fr
} 
A escola da periferia: escolaridade e segregação nos subúrbios

Isso se justificava pela desconfiança para com os poderes locais que, no final do século XIX, eram considerados imbuídos de idéias obscurantistas e de religiosidade, o que possibilitava clientelismos ou outras formas de favoritismo. Desse modo, a construção do sistema de ensino ocorreu de modo centralizado e vertical, fechado, como um lugar sagrado, a qualquer intrusão do exterior. Essa organização institucional dos estabelecimentos escolares continua muito valorizada pelos diversos funcionários e professores, e mais particularmente pelos sindicatos de docentes, que vêem nessa estruturação educativa todas as virtudes da escola pública e laica, pois permite que todas as crianças tenham acesso aos mesmos saberes escolares.

Boa parte dos funcionários e professores e de seus representantes (sindicatos) defendem essa idéia com mais afinco ainda, uma vez que as novas formas de organização dos estabelecimentos, oriundas das políticas de descentralização - autonomia dos estabelecimentos, aumento do papel do diretor do estabelecimento, relações com o meio etc. -, ocorrem no momento mesmo em que as diferenciações sociais se reforçaram no plano local.

Este é o objeto de pesquisa que Agnès Van Zanten constrói no intuito de apreender as configurações escolares particulares que surgem desde os anos de 1970, nas periferias, pelas características de seu público, pelas formas de funcionamento interno e pelas relaçóes que mantêm com o "centro".

No primeiro capítulo, a autora empenha-se em descrever o surgimento de "periferias" ou subúrbios que acumulam dificuldades sociais (desemprego, marginalização, exclusão social) e estabelecem relações específicas com o sistema escolar. Além disso, ela descreve "o crescimento e o declínio" dos subúrbios populares compostos por cidades operárias com formas de organização particulares, as quais favorecem a emergência de um modelo de integração segundo o modo de vida operário, e organizado pelo ritmo de trabalho na fábrica e as saídas de fim de semana (cinema, festas, piqueniques, estádios, bicicleta, pesca, jogo de baralho ou de dados etc.). Os imigrados integraram-se a esse modo de vida pela facilidade de acesso aos empregos abandonados pelos operários franceses (construção civil, por exemplo). Nesses subúrbios operários, ditos "vermelhos", pois eram, em sua maioria, administrados por eleitos comunistas, as orientações de desenvolvimento de atividades dentro e fora da escola constituem elementos fortes nas políticas. Como 
exemplo se podem citar a distribuição de refeições gratuitas ou de sapatos, as ações voltadas para atividades de lazer (colônias de férias no campo ou na praia) assim como o desenvolvimento de atividades depois das aulas, o subsídio ao transporte escolar e as atividades desportivas ou culturais. Trata-se de uma tentativa de orientar jovens e crianças que, entregues a si mesmos, poderiam optar por atividades delinqüentes. Desse modo, a influência ideológica exerce-se em torno das atividades escolares, e acaba levando a políticas sociais que privilegiam o desenvolvimento dos estabelecimentos escolares. Assim, a escola torna-se um campo emblemático nesses subúrbios operários onde a qualidade e a modernidade são parte das prioridades da população operária. Nos subúrbios parisienses, por exemplo, vários collèges e lycées dispõem de prédios, salas de aulas e auditórios modernos que rivalizam com os dos prestigiosos estabelecimentos parisienses que acolhem o público mais abastado das classes altas.

Desde os anos de 1960, e sobretudo de 1970, grandes conjuntos residenciais nos quais se preconiza a miscigenação social começam a ser construídos. Entretanto, a chegada de populações imigradas, geralmente oriundas de países recém-emancipados da dominação francesa, deixa claras as dificuldades de integração do modelo político da comunidade operária anterior.

Ao mesmo tempo, a crise do emprego agrava-se e acarreta vários problemas sociais. Esses subúrbios conhecem então o começo da estigmatização em razão das questões sociais que neles se desenvolvem (contestações sociais e políticas variadas) e a desqualificação social. Agnès Van Zanten empenha-se em descrever essa evolução, desde os anos de 1970, a qual leva à constituição das segregações urbanas cujos efeitos se estendem à escola. $\mathrm{O}$ declínio da população operária, o aumento do número de desempregados e a degradação social e urbana das cidades, grandes ou pequenas, e dos bairros surgem como uma construção política que repele os problemas sociais nas periferias, e, desse modo, cria espaços de relegação. A crise do emprego e a segregação espacial conduzem à explosão da violência urbana, do racismo popular etc.

Nos subúrbios, a renovação dos centros históricos transforma-os em lugares atraentes para as classes médias, que podem ter acesso à propriedade e empurram as classes desfavorecidas para partes e cidades mais afastadas, com menos recursos de transportes urbanos e equipamentos 
A escola da periferia: escolaridade e segregação nos subúrbios

desportivos ou culturais. Diante do tamanho da crise, as políticas municipais privilegiam as ações de prevenção, de inserção social e profissional e de luta contra a exclusão. A escola é fortemente afetada por esses fenômenos sociais que se instalam na periferia. Desde os anos de 1980, constatada a dimensão do fracasso escolar das crianças oriundas desse meio e em situação de exclusão social, os governos sucessivos vão desenvolver uma política de compensação: nessas "áreas sensíveis" são propostas "áreas de educação prioritária” que buscam "dar mais a quem tem menos", pela alocação de recursos específicos destinados a acompanhar o estudo escolar dos alunos, a desenvolver atividades outras que não escolares a fim de garantir a integração social, na medida do possível, e para reverter a atitude de fechamento sobre si mesmo que tende a predominar sobre as formas de sociabilidade comunitárias ou investidas anteriormente por forças políticas.

A partir da análise desse contexto, descrito em sua evolução e em suas características atuais, a autora analisa a atuação da escola nessa periferia. Eis como ela explica as estratégias dos pais, que caracteriza como retirada: a deserção das famílias das classes médias e até mesmo operárias "integradas" fez com que, nessas cidades e subúrbios, permaneçam essencialmente populações em crescente situação de pauperização. De origem estrangeira em sua maioria, essas populações recorrem a redes de vizinhança ou familiares densas. Essas famílias consideram a escola apenas um lugar de aprendizagem mais próximo de sua residência. Preocupaçōes de ordem da segurança (medo de assaltos, de violências físicas etc.) induzem alguns pais a mandar os filhos aos estabelecimentos mais próximos, garantia, a seus olhos, de controlar a educação de seus filhos. Algumas famílias de origem modesta manifestam uma indiferença relativa para com a escolarização dos filhos e os estabelecimentos escolares. Os problemas de indisciplina na escola ou no colégio são vividos como "incidentes de percurso". Essas famílias apenas passam a se sentir mais preocupadas com as questões de escolaridade de seus filhos quando de sua inserção profissional.

Em contrapartida, além das famílias desfavorecidas no plano tanto econômico como cultural, famílias de classes médias ou operárias com um emprego estável continuam presentes nesses subúrbios desqualificados. Pouco numerosas, elas se envolvem muito mais na escolaridade de seus filhos e participam da vida dos estabelecimentos. Elas demonstram sua fé nas virtudes da escola pública e investem na

Educ. Soc., Campinas, vol. 25, n. 86, p. 273-278, abril 2004 
melhoria do funcionamento desses estabelecimentos. Van Zanten revela mecanismos que concorrem à criação de percursos protegidos (táticas de aliança com os docentes, participação nas associaçôes de pais de alunos, "esquecimento" dos atos de indisciplina e de violência física ou verbal). Restam, entretanto, pais que adotam um comportamento de defecção para com a escola. Pela não-escolha de um estabelecimento, pela desmobilização para com a escolaridade de seus filhos, esses pais não acreditam na instrumentalização da escola para o futuro de seus filhos.

Agnès Van Zanten estabelece então um paralelo entre as estratégias dos estabelecimentos que, de fato, criam uma concorrência entre si, a qual acarreta uma submissão às pressões locais (eleitos, pessoas notórias, famílias etc.), e o desenvolvimento de lógicas de segurança, ao se adaptarem a seu meio institucional. $\mathrm{O}$ resultado dessa concorrência é a criação de classes de níveis diferentes (classes de niveau) ou de classes "boas" ou "ruins" que desempenham um papel determinante na carreira escolar das crianças. Essas estratégias coletivas ou individuais dos estabelecimentos criam novas formas de regulações que dão as costas ao modo de gestão centralizado, à manutenção das regras nacionais e preferem arbitragens segundo as condições locais, fundamentadas em arranjos e negociaçóes. Isso resulta numa tentativa de trabalho em conjunto entre o diretor do estabelecimento e o prefeito de uma comuna para reter os bons alunos ou evitar os que criam problemas graves; na criação de dispositivos financiados por autoridades locais; na implementação de comitês de ética para sensibilizar tanto as crianças como os pais aos valores morais a serem respeitados.

Em seguida, Van Zanten empenha-se em abordar o exercício profissional dos docentes nesses estabelecimentos "difíceis". Partindo das contribuições da sociologia das profissões, ela observa que os membros de uma profissão tendem a desenvolver uma imagem de seu "cliente ideal" a partir da qual modelam suas representações e práticas. Quanto mais importante a diferença entre o modelo ideal e a realidade, mais o profissional encontra dificuldades para adequar-se em seu exercício profissional. Este é o caso dos docentes dos subúrbios que foram formados para um certo tipo de aluno. É a questão da profissionalização que se coloca então, uma vez que, na França, os novos docentes começam sua carreira em estabelecimentos menos prestigiosos. De fato, a carreira dos docentes funciona menos em termos de verticalidade que pela mobilidade de um estabelecimento a outro, segundo o grau 
A escola da periferia: escolaridade e segregação nos subúrbios

de prestígio de que este goza. As estratégias então são as de evitação ou de sobrevivência pelo controle relacional e pedagógico em que a manutenção da ordem é o elemento central da atividade. Disso decorre a adaptação dos conteúdos e das práticas pedagógicos aos públicos desses estabelecimentos. Donde a autora considera que a adaptação contextual simboliza um processo de socialização profissional secundário no qual as relações com os colegas desempenham um papel importante. Segundo a autora, denota-se então uma clivagem entre docentes "antigos" e "novos": os primeiros apóiam-se em relaçōes "totais" entre os alunos e os colegas, ao passo que os "novos" buscam preservar seu campo de competência e se preservam assim das situações difíceis à espera de uma transferência.

$\mathrm{E}$ os alunos? A autora empenha-se em mostrar as atitudes diferenciadas segundo o tipo de organização social do estabelecimento: a existência de classes de níveis diferentes faz com que alunos até então envolvidos numa escolarização estudiosa (sétima série) desenvolvam estratégias contra a escola. Em contrapartida, a autora observa atitudes de solidariedade entre alunos, especificamente do mesmo grupo étnico, de integração na cidade ou no bairro e na escola pela integração em grupos de pares. Aqui, a atitude dos docentes (fatalistas, por exemplo) induz comportamentos de indiferença, desmobilização, indisciplina por parte dos alunos. A autora, ao fazer uma análise fina das práticas dos alunos, revela a capacidade que demonstram para resistir às normas impostas pela escola mas que talvez revele a apropriação, por esses alunos, da idéia de reprodução de sua posição de dominado no âmago da escola.

No final de seu trabalho, Agnès Van Zanten empenha-se para mostrar a estruturação de uma ordem social fundamentada na dualidade das posições - entre relegação e aumento da autonomia, entre resignação e vontade de enfrentar, entre docente e educador, entre bons pais e bons cidadãos, entre a acomodação e as tentativas de reapropriação, entre a ordem global e a ordem local -, que constitui a base das configuraçóes da escola da periferia ou dos pobres. Em outras palavras, ao tomar por base a escola da periferia, é a relação dentro dos estabelecimentos e seus vínculos com a dinâmica social do meio que a autora nos apresenta, abrindo assim um novo caminho para desdobrar as contribuições da sociologia das organizaçóes e da educação, o que permite renovar as análises sobre as questóes da escolaridade presentes na maioria das sociedades contemporâneas. 